\title{
Laser Ablation Cleaning Effects on Thermoluminescence Dating Technique
}

\author{
Diana Renzelli1, Simona Veltri², Fabio Stranges1,2, Pasquale Barone1, Marianna Barberio², \\ Fang Xu1 ${ }^{1}$, Assunta Bonanno ${ }^{1}$ \\ ${ }^{1}$ Department of Biology, Ecology and Earth Science, University of Calabria, Rende (CS), Italy \\ ${ }^{2}$ Physics Department, University of Calabria, Rende (CS), Italy \\ Email: diana.renzelli@unical.it
}

Received 15 May 2014; revised 23 June 2014; accepted 3 July 2014

Copyright (C) 2014 by authors and Scientific Research Publishing Inc.

This work is licensed under the Creative Commons Attribution International License (CC BY). http://creativecommons.org/licenses/by/4.0/

c) (i) Open Access

\begin{abstract}
In this work we present a study of laser ablation (LA) restoration techniques and of thermoluminescence dating process (TL). The main aim of the work is to demonstrate that LA don't affect the possibility to date ceramic artifacts after restoration. We ablate Neolithic ceramics in air with a first harmonic of laser YAG $(1064 \mathrm{~nm})$ and dating the artifacts before and after the cleanness process. We obtain a discrepancy of 200 years (3300 B.C. and 3100 B.C. before and after cleanness respectively), value which is in below limits of experimental error. Moreover, we monitor the temperature of artifacts during the LA at the point of sampling for dating. We observe that the maximum temperature reached is about $100^{\circ} \mathrm{C}$, not enough to empty the metastable traps that cause the luminescence signal.
\end{abstract}

\section{Keywords}

Laser Ablation, Ceramic Cleaning Process, Neolithic, Thermoluminescence

\section{Introduction}

Conventional methods in conservation are based on mechanical and chemical compound treatments. Mechanical cleaning is the most controllable method without introduction of chemical impurities into the artifact. However, this technique is applicable only in few cases because of damages that it can produce on artifacts. In fact, the mechanical removal of encrustation by mechanical instruments and abrasive particles can scratch the surface artifacts (Nikolov et al., 2004). In recent years, scientific investigation has led to the study of new technologies applied to cultural heritage (Ristic et al., 2010).

In this framework contactless methods, that do not damage the objects integrity, assume a strong importance. 
Among them, the laser methods are dominant.

Lasers are widely used in various fields of science, technology, art, and cultural heritage protection and optical methods that use lasers as light sources are applied in different diagnostics technique (Ristic et al., 2010). In particular, laser cleaning technique, based on the removing of the impurities through the process of laser ablation, LA, is frequently used in restoration of stone and ceramic artifact (Barberio et al., 2013; Salimbeni et al., 2000; Lanterna et al., 2000).

LA cleaning method possesses several advantages. As example the duration of restoration is very brief and the artifact surface is preserved. Moreover the operator can control the cleanness process monitoring the laser beam parameter (energy, power, pulse, irradiation time) without damage the constituent elements and removing only the surface patina impurity (Nikolov et al., 2004).

The LA techniques has a serious inconvenience that laser irradiation heats locally the surface artifacts and this can cause the impossibility of thermoluminescence (TL) dating after restoration. TL is, in fact, a technique which date materials starting from a heating at about $300^{\circ} \mathrm{C}$ (Aitken, 1985). Indeed, TL allows dating pottery or terracotta from the study of luminescence signals emitted by their crystalline components, such as quartz or feldspars (Aitken, 1985), therefore this luminescence emission is quenched by a heating at temperature greater than $250^{\circ} \mathrm{C}$ (temperature of bleaching of metastable traps in minerals).

The objective of this work is the study of the LA effects on the TL dating by monitoring the temperature of ceramic samples during the entire irradiation process and by the dating of the ceramic before and after LA.

\section{Materials}

Neolithic Sample (TOR, Figure 1) is found in the archeological excavation, "Piana di Curinga" (LameziaTerme, Cz, South Italy), dating back to the IV millenium B. C. (Renzelli et al., 2013). The Neolithic finding is an impressed ceramic and, in the first analysis, it appears made by a dark brown mixture and by a clay with several impurities; it belongs to the artistic culture of "Stentinello".

The "Stentinello" culture represents an evolution peculiar of the Neolithic culture of decorative techniques, during the diffusion of the Neolithic in the Southern Italy (Purri, 2007; Purri, 2011).

As well known, ceramic is a material composed by sedimentary rocks, clay and debris of variable mineralogical composition (as quartz, feldspar, calcium carbonates, oxides and hydroxides of iron and other minors as well as in organic matter and other various random materials) (Cuomo di Caprio, 2007).

\section{Methods}

As previously indicated, TL is a technique that allows us to dating pottery or terracotta, by analyzing the luminescence signals (Aitken, 1985) obtained heating the quartz and/or feldspar content in the samples. The artefact, after the last heating in the oven, begins again to accumulate a certain amount of absorbed dose ("Equivalent dose") due to the natural radiation coming from the ceramic itself (U, Th, K-40) and from the surrounding environmental gamma rays plus cosmic radiation. The subsequent heating to high temperatures in laboratory, results

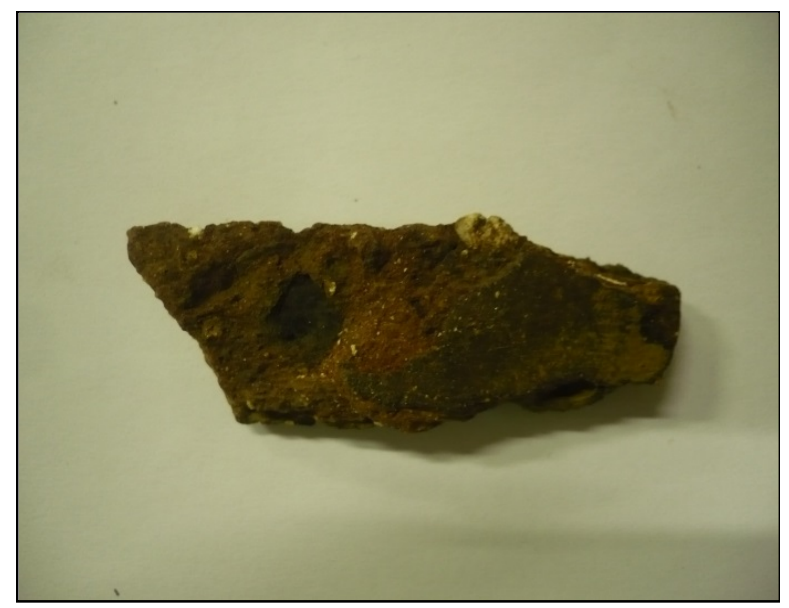

Figure 1. Neolithic sample (TOR). 
in the release of the light corresponding to the dose accumulated over time (Murray \& Wintle, 2000; Aitken, 1985). From light emitted study, it is possible to calculate the time elapsed since the original heating in the oven, according to the equation age (Aitken, 1985; Furetta \& Gonzàlez Martinez, 2007) expressed in years:

$$
\text { Age= Equivalent Dose(Gy)/Annual Dose(Gy/year) }
$$

where, the "Annual dose $(A D)$ " (Gy per years) is the annual natural radiation and "Equivalent dose (ED)" is the dose adsorbed by crystal in Gray (Gy).

The Neolithic artifact (see Figure 1) is dated by a Single Aliquot Regenerative-dose protocol, SAR (Hong et al., 2006), and the obtained results will be compared with the historical data, to confirm the authenticity and to classify the findings (Renzelli et al., 2013).

The procedure based on a SAR (Gattuso et al., 2012) has the advantage, over the traditional methods (Multiple Aliquot Additive Dose, MAAD), of avoiding standardization or sensitivity problems and reduces the effort required in sample preparation. The SAR protocol has been discussed by Murray and Wintle (2000) who proposed a modified regeneration method with respect to the conventional one (Murray \& Roberts, 1998; Murray \& Wintle, 2000; Hong et al., 2006).

\section{Sampling and Analytical Procedure}

\subsection{Sampling for TL Dating}

Sample preparation took place in condition of darkness with the aid of a single soft red light (>600 nm). We have chosen the Quartz inclusion technique, since with this method we obtain grains of larger size that can then be submitted to acid solution to eliminate surface carbonates (Fleming, 1979).

The first step of preparation involved sampling (using a low speed drill) in the sample bulk, in order to avoid external contamination, such as, sources of light mostly, heat or radiation to which the sample surfaces may have been exposed after the discovery.

Grain size 63 - $125 \mu \mathrm{m}$ was sieved and treated with $10 \% \mathrm{HCl}$ to eliminate any present carbonates and bath with $30 \% \mathrm{H}_{2} \mathrm{O}_{2}$ to eliminate organic material. The so obtained different crystalline fractions were separated by using a heavy liquid solution.

The quartz grains were then extracted, dried and used for the dating process. These grains were fixed with silicone oil on stainless steel discs of $9.7 \mathrm{~mm}$ in diameter and then loaded on the spectrometer.

\subsection{TL Dating Analytical Procedure}

The dating has been obtained via thermoluminescence measurements using a TL reader from Risø TL/OSLDA-20, by applying the SAR protocol. For the artificial doses we use a beta source (90Sr) characterized by a dose rate of $0.1 \mathrm{~Gy} / \mathrm{sec}$. Generally we used a heating rate of $5^{\circ} \mathrm{C} / \mathrm{s}$ up to a temperature of $450^{\circ} \mathrm{C}$ and the samples were irradiated with ten regeneration doses.

The standard Photo Multiplier Tube (PMT) in the Risø TL/OSL reader is a bialkali EMI 9235QB PMT, which has maximum detection efficiency between 200 and $400 \mathrm{~nm}$, making it suitable for detection of luminescence from both quartz and feldspar. The Risø TL/OSL reader used with the following detection filter: Hoya U-340 (7.5 $\mathrm{mm}$ thick, diameter $\varnothing=45 \mathrm{~mm}$ ).

\subsection{TL Measurement before and after Cleaning Process}

The cleaning process of all pottery surface was obtained by LA, in order to detect the possible influence of LA on the intensity of the natural thermoluminescence (NTL) signal. In fact, LA was conducted in dark conditions and the TL measurement was taken before and after cleaning process.

The LA was carried out in air positioning the sample in front of the first armonic $(1064 \mathrm{~nm})$ of a laser Nd:YAG (Quanta-Giant Series 710), with a power of $420 \mathrm{~mJ} /$ pulse (Barberio et al., 2013), a frequency of $20 \mathrm{~Hz}$ and spot size of laser beam on the surface of the sample of $4-5 \mathrm{~mm}$. Each ablation was conducted with an irradiation time of 30 minutes. The possible influence of the LA on the intensity natural of the thermoluminescence was verified monitoring the temperature of ceramic samples during the entire irradiation with the laser beam. The temperature was measured by a J-type thermocouple installed in a cavity in the ceramics (Figure 2) 


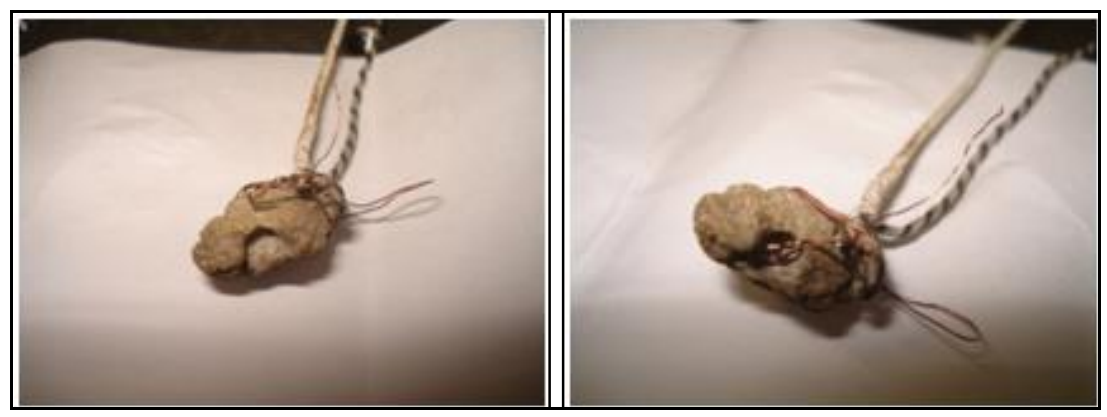

Figure 2. J-type thermocouple installed in the cavity of material recovery for TL.

obtained in the front of laser beam and at a depth usually used for TL sample taking (few millimeters over ceramic surfaces).

\section{Analysis Methods}

The determined Equivalent doses (ED) of the Neolithic sample is reported in Table 1. In particular, the table shows the results obtained before and after treatment with LA.

The value of the ED is the mean value over all the measurements for which the sensitivity correction has been successful.

The correction for sensitivity changes was made by monitoring the luminescence response of the sample to a subsequent test dose of $1 \mathrm{~Gy}$, given to the sample after measuring the natural dose and after each regeneration step, as resumed in Table 2. The correction procedure consists in normalizing each measurement to the intensity of the relative test dose. Because the first regeneration dose equals to the last regeneration, the TL normalized intensities for these two regeneration doses should be identical if the correction is successful (Renzelli, 2010; Renzelli et al., 2013).

Figure 3 and Figure 4 show examples of the sensitivity-corrected TL signal versus radiation dose. The data of the growth curve, corrected for sensitivity, were fitted by a linear function. The ED was calculated from the growth curve extracting its value at the corrected NTL.

The $\mathrm{AD}$ has been determined by measuring the natural radiation coming from the ceramic itself due to their content in radioactive elements ( $\mathrm{U}, \mathrm{Th}, \mathrm{K}-40$ ), adding then gamma and cosmic radiation from the surrounding (Renzelli et al., 2013). The data on radioactive content of K, Th and U are obtained by Laser Ablation-Inductively Coupled Plasma-Mass Spectrometry (LA-ICP-MS) and converted to infinite matrix dose using the conversion factors by Adamiec and Aitken (Adamiec \& Aitken, 1998). Contributions from cosmic rays were included using the equations given by Prescott and Hutton (Prescott \& Hutton, 1994). The contribute of cosmic rays is in agreement with that obtained by Bianca et al. (Bianca et al., 2011) for the same geographical area. The AD has been corrected using, for the moisture rate (W), the water content attenuation factor given by Zimmerman (Zimmerman, 1971) and the size attenuation factors of Mejdahl (i.e. 1.25 for beta and 1.14 for gamma contributions) (Mejdahl, 1979).

The results of the dating obtained show the compatibility of the results both before and after treatment with LA.

The temperature of the sample rises (as visible in Figure 5) during the first minutes of ablation reaches a value of saturation which remains unchanged during the entire process of ablation. The temperature achieves a saturation value of about $100^{\circ} \mathrm{C}$, value very far from what necessary to empty metastable traps, which are above $270^{\circ} \mathrm{C}$.

\section{Results and Conclusions}

In this work we demonstrate that LA cleaning process do not affect the possibility to date a ceramic artifact after restoration process. The ablation process was conducted for 30 minutes using a first harmonic $(1064 \mathrm{~nm})$ of YAG laser with an energy of $420 \mathrm{~mJ} /$ pulse while dating were taken by SAR protocol.

We date a Neolithic ceramics before and after LA obtaining results perfectly compatible. The samples were, in fact, dated at 3300 B.C. when the sample for TL is taken before LA and at 3100 B.C. after LA, the difference 
Table 1. Equivalent Dose (ED) and TL dating of the samples as obtained using TL data based on the S.A.R. protocol. The label " $\mathrm{N}^{\circ}$ " indicates the number of measurements for which the sensitivity correction has been successful. The table shows the results obtained before and after treatment with Laser Ablation.

\begin{tabular}{ccccccc}
\hline “TOR” Sample & $\mathrm{N}^{\circ}$ & $\mathrm{ED}(\mathrm{Gy})$ & $\mathrm{AD}(\mathrm{mGy} / \mathrm{a})$ & Age (a) & TL Dating & Site historical dating \\
\hline before LA & 3 & 12.2 & $2.3 \pm 0.1$ & $5300 \pm 400$ & $3300 \pm 400$ B.C. & "Stentinello” Culture-IV millennium B.C. \\
after LA & 3 & 11.8 & $2.3 \pm 0.1$ & $5100 \pm 800$ & $3100 \pm 800$ B.C. & "Stentinello” Culture-IV millennium B.C. \\
\hline
\end{tabular}

Table 2. Sequence illustrating an example of the procedure for S.A.R. measurements adopted in this study.

\begin{tabular}{cccc}
\hline Step & Sequence & & \\
\hline 1 & $\mathrm{NTL} 450^{\circ} \mathrm{C}, 5^{\circ} \mathrm{C} / \mathrm{s}$ & & Label \\
2 & $\operatorname{Irr} \beta 1 \mathrm{~Gy}+\mathrm{TL}$ & Test dose & NTL \\
3 & $\operatorname{Irr} \beta 2 \mathrm{~Gy}+\mathrm{TL}$ & First Regenerative dose & First TL 2Gy \\
4 & $\operatorname{Irr} \beta 1 \mathrm{~Gy}+\mathrm{TL}$ & Test dose & Test TL 2Gy \\
- & - & - & - \\
$\mathrm{x}$ & $\operatorname{Irr} \beta \mathrm{x} \mathrm{Gy}+\mathrm{TL}$ & "x” Regenerative dose & TL “x” Gy \\
- & $\operatorname{Irr} \beta 1 \mathrm{~Gy}+\mathrm{TL}$ & Test dose & Test TL “x” Gy \\
- & - & - & - \\
- & $\operatorname{Irr} \beta 2 \mathrm{~Gy}+\mathrm{TL}$ & Last Regenerative dose & Last TL 2Gy \\
- & $\operatorname{Irr} \beta 1 \mathrm{~Gy}+\mathrm{TL}$ & Test dose & Test TL 2Gy \\
\hline
\end{tabular}

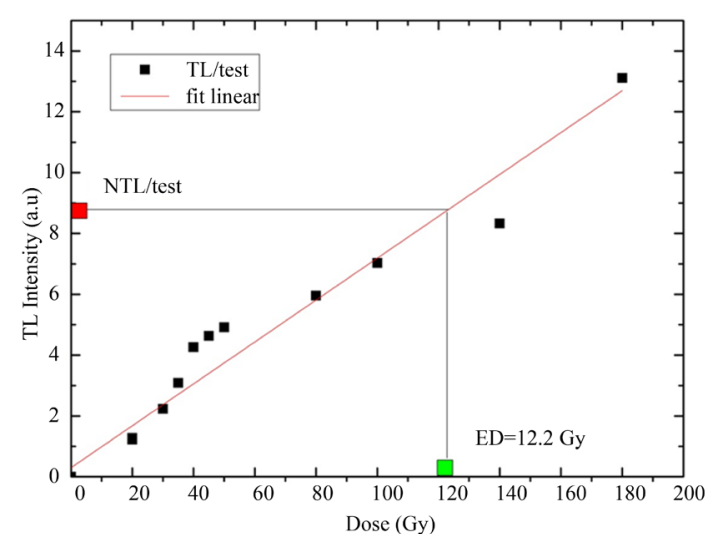

Figure 3. Determination of the Equivalent Dose, ED, of Neolithic sample, before Laser Ablation, based on the Single Aliquot Regenerative-dose (SAR) protocol. The experimental points are fitted by a linear function.

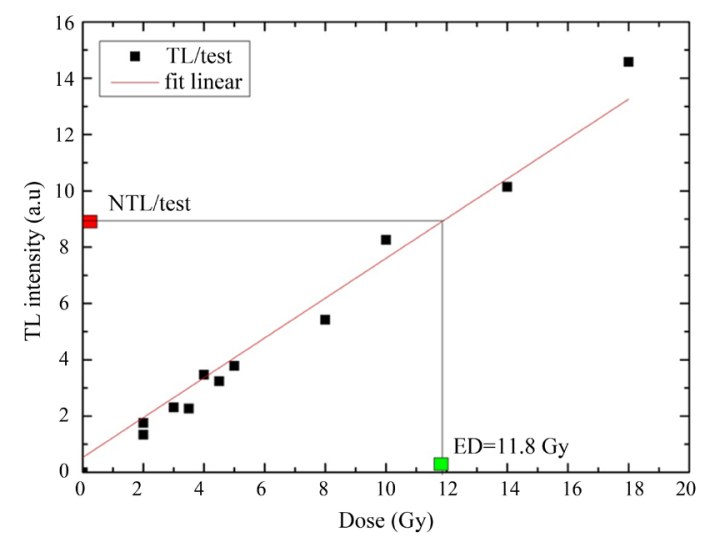

Figure 4. Determination of the Equivalent Dose, ED, of Neolithic sample, after Laser Ablation, based on the Single Aliquot Regenerative-dose (SAR) protocol. The experimental points are fitted by a linear function. 


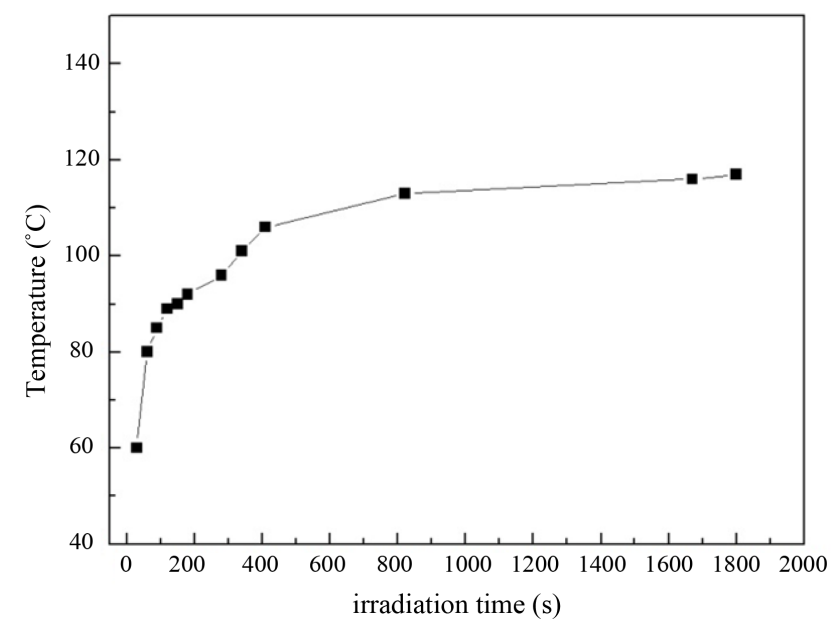

Figure 5. Monitoring of the temperature during the ablation process.

of 200 years is below the limits of experimental errors. Moreover we monitoring during all laser ablation cleaning process the sample temperature in the cavity for TL sample taking. The results show that temperature increases in the first minutes of irradiation reaching a saturation value of about $100^{\circ} \mathrm{C}$ while the metastable traps are empties only at temperature greater than $270^{\circ} \mathrm{C}$.

\section{Acknowledgements}

This work has been funded from the European project PON01_02140 “COMAS”.

\section{References}

Adamiec, G., \& Aitken, M. J. (1998). Dose-Rate Conversion Factors: Update. Ancient TL, 16.

Aitken, M. J. (1985). Thermoluminescence Dating. London: Academic Press, 153.

Barberio, M., Stranges, F., Renzelli, D., Barone, P., Xu, F., \& Bonanno, A. (2013). Laser Ablation Process on Ceramic Artifacts: Study of Application to “Caroselli”. Journal of Physical Science and Application, 3, 224-228.

Bianca, M., Catalano, S., De Guidi, G., Gueli, A. M., Monaco, C., Ristuccia, G. M., Stella, G., Tortorici, G., Tortorici, L., \& Troja, S. O. (2011). Luminescence Chronology of Pleistocene Marine Terraces of Capo Vaticano Peninsula (Calabria, Southern Italy). Quaternary International, 232, 114-121. http://dx.doi.org/10.1016/j.quaint.2010.07.013

Cuomo di Caprio, N. (2007). Ceramica in Archeologia 2. Antiche tecniche di lavorazione e moderni metodi di indagine. Roma: L’Erma di Bretschneider.

Fleming, S. J. (1979). Thermoluminescence Techniques in Archaeology. New York: Oxford University Press.

Furetta, C., \& Gonzàlez Martinez, P. R. (2007). Termoluminescenza e Datazione. Roma: Bagatto Libri.

Gattuso, C., Renzelli, D., Barone, P., Pingitore, V., \& Oliva, A. (2012). SAR and MAAD TL Dating of “Caroselli” from Three Sites in Calabria, South Italy. Mediterranean Arhaeology and Archaeometry, 12, 43-54.

Hong, D. G., Kim, M. J., Choi, J. H., El-Faramawy, N. A., \& Goksu, H. Y. (2006). Equivalent Dose Determination of Single Aliquot Regenerative-Dose (SAR) Protocol Using Thermoluminescence on Heated Quartz .Nuclear Instruments and Methods in Physics Research B, 243, 174-178. http://dx.doi.org/10.1016/j.nimb.2005.05.059

Lanterna, G., \& Matteini, M. (2000). Laser Cleaning of Stone Artefacts: A Substitute or Alternative Method? Journal of Cultural Heritage, 1, S29-S35. http://dx.doi.org/10.1016/S1296-2074(00)00136-9

Mejdahl, V. (1979). Thermoluminescence Dating: Beta-Dose Attenuation in Quartz Grains. Archaeometry, 21, 61-72. http://dx.doi.org/10.1111/j.1475-4754.1979.tb00241.x

Murray, A. S., \& Roberts, R. G. (1998). Measurement of the Equivalent Dose in Quartz Using a Regenerative-Dose Single-Aliquot Protocol. Radiation Measurements, 29, 503-515. http://dx.doi.org/10.1016/S1350-4487(98)00044-4

Murray, A. S., \& Wintle, A. G. (2000). Luminescence Dating of Quartz Using an Improved Single Aliquot Regenerative-Dose Protocol. Radiation Measurements, 32, 57-73. http://dx.doi.org/10.1016/S1350-4487(99)00253-X

Nikolov, I., Popmintchev, T., Todorov, T., Buchvaron, C., Surtchev, M., \& Tzaneva, S. (2004). Laser Restoration of Ceramic Artifacts with Archeological Value. Applied Physics A Material Science and Processing, 79, 1111-1115. 
Prescott, J. R., \& Hutton, J. T. (1994). Cosmic ray Contributions to Dose-Rates for Luminescence and ESR Dating: Large Depths and Long Terms Time Variations. RadiationMeasurements, 23, 497-500. http://dx.doi.org/10.1016/1350-4487(94)90086-8

Purri, R. (2007). Elementi di cultura materiale nel Neolitico Lametino, ricerca e sperimentazioni su manufatti del Neolitico di Piana di Curinga. Soveria Mannelli (Cz): Calabria Letteraria Editrice.

Purri, R. (2011). Il Neolitico a Piano di Curinga_Laboratorio di Archeologia sperimentale. Soveria Mannelli (CZ): Calabria Letteraria Editrice.

Renzelli, D. (2010). Implementazione del protocollo S.A.R. per la Luminescenza e Datazione di Caroselli calabresi. Thesis, Arcavacata di Rende (Cosenza): University of Calabria.

Renzelli, D., Barone, P., Pingitore, V., Sirianni, F., Purri, R., Davoli, M., Barca, D., \& Oliva, A. (2013). SAR TL Dating of Neolithic and Medieval Ceramics from Lamezia, Calabria (South Italy): A Case Study. Mediterranean Archaeology and Archaeometry, International Scientific Journal, 13, 277-288.

Ristic, S., Polic-Radovanovic, S., Katavic, B., Kutin, M., Nikolic, Z., \& Puharic, M. (2010). Ruby Laser Beam Interaction with Ceramic and Copper Artifacts. Journal of Russian Laser Research, 31. http://dx.doi.org/10.1007/s10946-010-9158-y

Salimbeni, R., Pini, R., Siano, S., \& Calcagno, G. (2000). Assessment of the State of Conservation of Stone Artworks after Laser Cleaning: Comparison with Conventional Cleaning Results on a Two-Decade Follow up. Journal of Cultural Heritage, 1, 385-391. http://dx.doi.org/10.1016/S1296-2074(00)01094-3

Zimmerman, D. W. (1971). Thermoluminescent Dating Using Fine Grains from Pottery. Archaeometry, 13, $29-52$. http://dx.doi.org/10.1111/j.1475-4754.1971.tb00028.x 
Scientific Research Publishing (SCIRP) is one of the largest Open Access journal publishers. It is currently publishing more than 200 open access, online, peer-reviewed journals covering a wide range of academic disciplines. SCIRP serves the worldwide academic communities and contributes to the progress and application of science with its publication.

Other selected journals from SCIRP are listed as below. Submit your manuscript to us via either submit@scirp.org or Online Submission Portal.
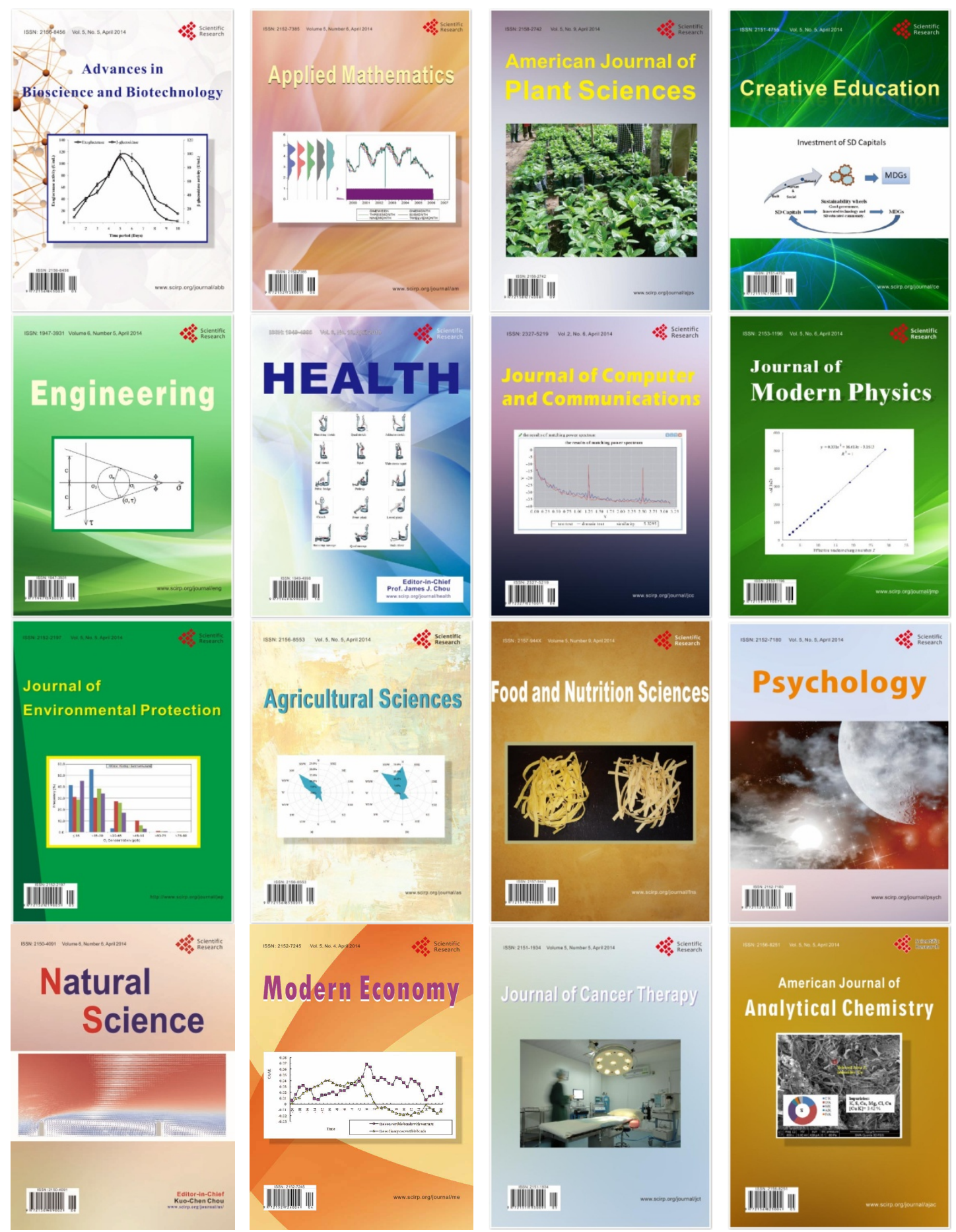